\title{
Protection and Development of Dong Nationality Settlement Pattern in Guangxi from the Perspective of Ecology
}

\author{
Wenshuang Zhu \\ School of Arts, Guilin University of Technology, 541004, Guilin, Guangxi, China \\ zzhll@163.com
}

Keywords: Ecology; Dong nationality settlement; Nature; Development

\begin{abstract}
The Dong nationality settlement in Guangxi is a human settlement paradigm that is shaped by the Dong people in the natural system with the rule of protecting and making use of land and natural resources and that integrates natural ecology and humanity ecology. It conforms to nature, is a part of nature and respects nature. Its recycling ecologic environment is discussed to analyze the crisis faced in the development of existing traditional space and pattern of Dong settlement and put forward the measures of protection and development so as to protect and develop to an extent the continuity of settlement history, culture-enriched customs and the integrity, continuity and original nature of settlement space and pattern.
\end{abstract}

\section{Introduction}

It was first declared in the medical book titled Airs, Waters, and Places by Hippocrates that our lives, whether being ill or healthy, are closely related to the power of nature; nature must never be resisted and conquered. Instead, its advice must be understood and it is to be treated as an ally.

However, with the rapid urbanization, exaggerated invasion and destruction against nature by humans have led to irreversible damages to nature. The villages once pacifying and comforting our soul are trapped in frustration and desperation arising from being surrounded by industrial cities.

Guangxi is one of the regions with less developed industry in China and also a place where 11 minorities settle. It may be the absence of dazzling high buildings, decorated industrial products and viaducts which are seen everywhere that contributes to existence and development of these ethic minority settlements. Dong nationality is a village with better development and preserved and developed settlement pattern. The village keeps its self-nature maintained and lives in harmony with nature in a greed and lure-filled world as it gets close to nature and is complacent and conservative. However, the nature of Guangxi Dong nationality is getting lost under the impact of the over-all situation.

\section{Ecology of Dong Nationality Settlement Pattern}

According to the meaning of society, settlement has various interpretations as a community. A romantic interpretation says that settlement that serves as a community of shared land and means of production is the community where humans and nature live in harmony with each other. Villages, as the most primitive and fundamental form of existence, resemble much with natural phenomena in terms of relational features[1].

Settlement Site: Conforming to Nature. The Dong nationality settlements in Guangxi are situated within Sanjiang Dong Autonomous County with complex and diverse landforms, more mountains and fewer flat lands. Despite the strong desire of Dong people to transform nature, the site of settlements comes with much dependence on and conformity with nature. The settlement site is determined according to actual conditions and always sits by the mountains and rivers. Farmlands are made use of and the slope environment is dealt with.

The Dong nationality settlements in Guangxi are classified into two categories by the geographic features of the site.

One is the village on mountains and valleys. These villages are situated on the cliff, 
mountainside or slopes of high mountains. Buildings are built eastwards or southwards by the mountain to receive sunlight, escape from the cold and get ventilated. Linlve Village in Sanjiang, for example, is situated on the south slope of a high mountain for favorable orientation and ventilation, avoidance of place that may lead to natural disasters including gullies (Fig. 1).

The other one is the villages at hills and on flatlands. These villages are vast in numbers, widely distributed and deeply influenced by geomantic conception. They are geologically located on gentle slopes at the foot of hills or by the mountain or lie in valleys. For environmental features, these mountains are situated by the mountains, rivers or near farmlands. Chengyangba Village and Bazuo Village in Sanjiang, for example, are spreading all over the side of creeks or rivers and are connected (refer with: Fig. 2).

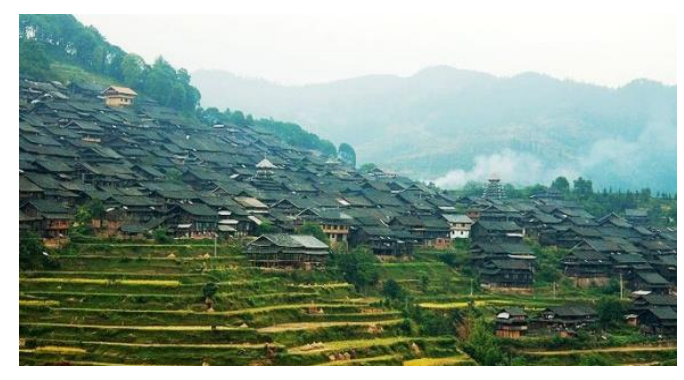

Figure 1. Linlve Village, Sanjiang

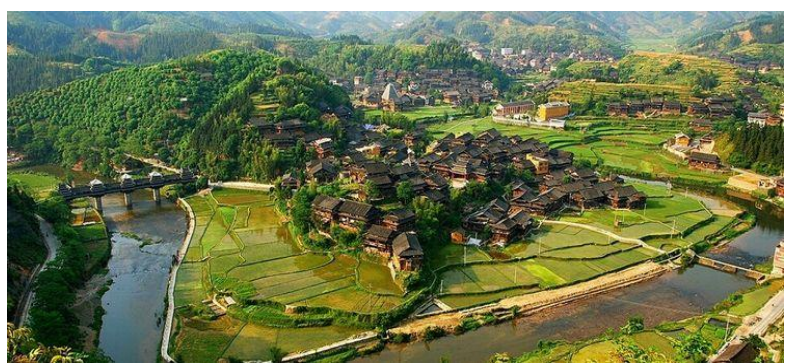

Figure 2. Chengyangba Village, Sanjiang

Settlement Space: Being a Part of Nature. Drum towers, ancestral temples, stages and dwellings, hacks, airing racks, storages, village gates, pavilions and wind-rain bridges as well as singing yards in front of drum towers are essential for a typical Dong settlement space.It seems that buildings everywhere are randomly scattered. However, they shape the "spatial network" with the naturally intrinsic connections and echo with nature. Seemingly, they are born from nature.

Road. With reference to LIN Qi's concept of road, roads in the image of Dong settlement space are not merely traffic passages. For Dong residents, the road is a key element in the image. Roads refer to conventional, accidental or potential mobile channels of observers. They may be down-top mountain roads, footways in the farmlands, gravel roads at river and stream sides or the wind-rain bridges crossing the waters. These roads bring people the charm of nature.

Boundary. The horizontal boundaries of the Dong nationality settlements are unclear: they are roads that fade away, flowing streams or discontinuous paddy fields. Set off by mountains and trees, these horizontal interfaces are disappearing in the hazy nature. On the contrary, the vertical boundaries of the settlements get clear because of ups and downs of mountains and structured building forms[2]. The difference between ambiguity and clarity enables the villages to bring people a feeling that they are born from nature, which develops the lyrical country feelings.

Joint. The joint is the center where traveling people get together. It is a connecting point, the rest area of the traffic line or the crossing or junction point of roads or a conversion position from one structure to the other structure or merely a rallying point [3].Different from those in cities, the joints in the Dong nationality settlements are often under the influence of natural environment. Roads take a natural turn by the mountain and water, turning joints to be more meaningful. For examples, wells, pavilions, drum towers and wind-rain bridges inherit the way as roads take, not only adapting to landform changes but also bring the residents a sense of belonging and power of cohesion.

Area. Areas in the Dong nationality settlements are not as complex as those in cities. Often, functional areas are defined according to changes in the natural environment. Maan Village in Sanjiang, for example, have planting areas consisting of terrace fields and slopes at surroundings. The flatlands at the foot of mountains and surrounding the drum tower are communication areas. The village space between planting areas and communication areas serves as the residential area.

The Dong inhabitants induce the power of settlement space with the potential power in natural topography. They increase the force of the field and further enhance the power of cohesion and raise a sense of belonging of settlements by keeping the settlement and natural environment the same[4].

Existence of Settlement:Respecting Nature. Respecting nature requires harmony and unity of 
humans and nature. In a whole, the culture of Dong nationality settlement is the typical farming culture. Upon selection of a settlement site, enough fields surrounding the villages are needed for purpose of production and existence. In addition, proper distance between settlements and between villages is needed for production and activity. For this reason, villages are often built based on fields, by mountains or faces fields or along riversides. These villages are developed into the space where settlements exist in the most harmony with nature.

Respecting nature is to maintain the gift of nature. By the mountains - it is to respect the mountain. The Dong nationality settlements are built in the shape of mountains. Mountains and forests are maintained behind the houses. Mountain roads bend treacherously in front of houses. By the river - it is to respect the water. Ponds, wells and ditches and river dams and waterwheels in the Dong villages are scattered along rivers. Aquatic plants grow by the river. Waterfowls enjoy themselves on water surface.Near farm fields - it is to respect the fields. In mountainous areas, the "rice-fish-duck" pattern guarantees fertilized farmlands. It is for this reason that soil in the land will not get barren due to cropping that is an activity of deprivation similar to mining and consumes the materials accumulated over the time and with countless lives [5].

Respecting nature requires restricting and prohibiting humans from utilizing the value of nature. With the increasing population of the Dong Nationality, part of the population will certainly move out to develop new settlements when the settlement scale develops to the afterward limit of bearing capacity of nature. The latter may be connected with the former by intermarriage and taking part in the sacrificial activities of the former settlement[6].

\section{Crisis of the Existing Dong Nationality Settlement Pattern}

Damage to Natural Environment. Rapid urbanization and self-driving travel boom as well as the previous slogans saying "want rich, build a road first" result in cruel exploration of mountain roads in the Dong village settlements and even several roads pass through certain Dong villages, which breaks the spatial patter of the Dong nationality settlements that are cohesive and centered. Mountains are cut and gullies are filled for vehicles with hazardous emissions. Does such concrete express highway really take away the pain of building roads?

Damage to Human Settlement. Modern brick buildings imitating urban styles are built in the Dong villages, which results in fewer and fewer traditional wooden buildings. Does Dong people's favor of modern components and their random replacement of roofs, toilets, kitchens and stairs really protect and develop the so-called "out-dated" items of the traditional style[7]?

Damage to Cultural Environment. Many villagers yearn for the wonderful outside world. New lifestyles fade the tradition of life in Dong nationality passing down for several hundred years. Residents in several settlements do not allow for selection of a site. Instead, they build their new houses outside the villages with their preferences, providing no transition zone and continuity with original villages and thus leading to unpleasant landscape where old and new villages are totally different and incompatible with each other[8]. How can the over-all style and cultural characteristic of the traditional Dong nationality settlement be passed down?

\section{Measures for Protection and Development of the Dong Nationality Settlement Pattern}

Raising the Awareness of Ecological Civilization Development. Villagers should be guided not to show too much envy for urbanization construction. Villagers should be trained on a regular or irregular basis in terms of knowledge or skills of agricultural planting, livestock breeding, ecological construction and civilized and healthy life. The consciousness of ecological civilization and sense of responsibility should be raised; the long-term awareness of ethnicity existence should be set up, and; the ecological value that humans and nature develop in harmony should be set up. It should be promoted that excessive tourism development that destroys the spatial pattern and style of traditional Dong villages should not be taken even under the attack by business economy[9].

Developing the Mechanism of Ecological Civilization Construction. Developing the management mechanism: we should promote the policies and documents including the management 
of ecological functional zoning of ancient villages, ecological resource management, nature reserve management and circular economy development. We should legally protect the ecological environment of ancient villages.

Developing the economic mechanism: we should establish the compensation mechanism taking financial transfer payment as a major way for ecological civilization construction of ancient villages and a diversity of investment mechanism where social capital is input for ecology protection programs of ancient villages. Mechanisms should be used to guarantee that funds for ecological civilization construction of ancient villages are put in place.

Developing the talent mechanism: we should introduce more outstanding design talent and local constructors who love and promote protection and development of ancient villages for joint maintenance.

Establishing a Dong Humanistic Ecosystem. The Dong people and the natural process will be merged into a seamlessly organic whole by integrating the agricultural production, the habitat of wild fauna and flora, recreation and entertainment, residential space, resource saving, water and nutrient cycling as well as visual beautification into the dependent network. And this will be the best interpretation of the Dong humanistic ecosystem[10].

Its stability depends on the energy and wisdom of humans and also of nature. If the act that we design and manage the ecosystem is right and proper, the Dong nationality settlements and nature will be necessarily symbiotic.

\section{Summary}

For the environmental order, these settlements are ecological, sustainable and self-recycling environment system that implies the beauty of the Dong nationality, the place and culture in Guangxi and shapes characters and qualities of Guangxi Dong nationality settlements that cannot be reproduced.

\section{Acknowledgements}

This paper is one of the phased objectives of the topic titled "Research on Protection and Development of Dong Nationality Settlement Pattern in Guangxi from the Perspective of Ecology" of the philosophy and social science program in Guangxi (13FMZ010).

\section{References}

[1] (Japan) Written by Hiroshi Hara, Translated by YU Tian, LIU Shumei. Syuraku No Oshie 100 [M]. Beijing: China Architecture \& Building Press, 2003

[2] ZHENG Jingwen. Research on Settlement Space of Minorities in Northern Guangxi [D]. Huazhong University of Science and Technology: 2005

[3] (Britain) Written by Cliff Mansfuting, Translated by ZHANG Yonggang, LU Weidong. Street and square [M]. Beijing: China Architecture \& Building Press, 2004

[4] (Japan) Written by Fuji Aki, Translated by NING Jing, WANG Jun. Visit the settlement [M]. Beijing: China Architecture \& Building Press, 2003

[5] (USA) Ian Lennox McHarg, Translated by Rui Jingwei. Design with Nature [M]. Tianjin University Press

[6] ZHAO Xiaomei, Jiayue. Arrangement and development of Dong settlements [J]. Community Design, 2012, (02): 45

[7] SHI Yin. Theory of dong village of ecological protection--to liuzhou sanjiang Cheng Yang eight village as an example [J]. China Ancient City, 2013, (04): 62

[8] LIU Xiaoman. Preliminary exploration on the ecological civilization construction of ancient Villages protection --Take the ancient Village of Minority Dong as an example [J]. Chinese and Overseas Architecture, 2014, (09): 97 
[9] HUANG Xianqin, ZHOU Chuanyan, LUO Shiqin, TANG Jingang. The relationship between Qiandongnan Miao-Dong ethnic cultures and ecological civilization building [J].Guizhou Science,2013,(04): 85

[10] WEN Zhi. Ecological civilization construction to "dance with nature[J].Resources and Habitant Environment,2016,(01):37 